\title{
Advances in Novel Low-Macroscopic Field Emission Electrode Design Based on Fullerene-Doped Porous Silicon
}

\author{
Rostislav Smerdov ${ }^{1, *}$, Yulia Spivak ${ }^{2}$, Ivan Bizyaev ${ }^{3}$, Pavel Somov ${ }^{4}$, Victor Gerasimov ${ }^{5}$, Alexander Mustafaev ${ }^{1}$ \\ and Vyacheslav Moshnikov ${ }^{2}$ \\ 1 Department of General and Applied Physics, Saint Petersburg Mining University, \\ 199106 St. Petersburg, Russia; alexmustafaev@spmi.ru \\ 2 Department of Micro- and Nanoelectronics, Saint Petersburg Electrotechnical University "LETI", \\ 197376 St. Petersburg, Russia; ymkanageeva@yandex.ru (Y.S.); vamoshnikov@mail.ru (V.M.) \\ 3 Self-Organizing High-Temperature Nanostructures Laboratory (SVN), Peter the Great St. Petersburg \\ Polytechnic University, 195251 St. Petersburg, Russia; IvanBiziaev@yandex.com \\ $4 \quad$ TESCAN CIS Ltd., 195220 St. Petersburg, Russia; pavel.somov@tescan.ru \\ 5 Department of Mechanics and Control Processes, Peter the Great St. Petersburg Polytechnic University, \\ 195251 St. Petersburg, Russia; gerasimov_vi@spbstu.ru \\ * Correspondence: rostafan@gmail.com
}

check for updates

Citation: Smerdov, R.; Spivak, Y.; Bizyaev, I.; Somov, P.; Gerasimov, V.; Mustafaev, A.; Moshnikov, V. Advances in Novel Low-Macroscopic Field Emission Electrode Design Based on Fullerene-Doped Porous Silicon. Electronics 2021, 10, 42. https://doi.org/10.3390/ electronics10010042

Received: 16 November 2020 Accepted: 24 December 2020 Published: 29 December 2020

Publisher's Note: MDPI stays neutral with regard to jurisdictional clai$\mathrm{ms}$ in published maps and institutional affiliations.

Copyright: (C) 2020 by the authors. Licensee MDPI, Basel, Switzerland. This article is an open access article distributed under the terms and conditions of the Creative Commons Attribution (CC BY) license (https:// creativecommons.org/licenses/by/ $4.0 /)$.

\begin{abstract}
Perspective low-macroscopic field (LMF) emission prototype cathodes based on fullerene $\mathrm{C}_{60}$ doped porous silicon were realized via a two-stage technique comprising the electrochemical etching process of a monocrystalline silicon wafer and functionalization of the acquired porous silicon (PS) matrix with silver-doped fullerene-based carbon structures. The resulting LMF cathode prototypes were studied with SEM and EDS techniques. The formation of an amorphous silver-doped $\mathrm{C}_{60}$-based layer consisting of nanosized aggregates on the matrix surface was established. The emission characteristics of the prototypes were analyzed, crucial parameters including threshold field strength values, emission current density, and effective potential barrier height for electrons were considered. A novel LMF emission model is suggested. It was established that the emitter prototypes realized during this study are on par with or superior to modern and promising field cathodes.
\end{abstract}

Keywords: field emission; composite nanostructures; fullerene $\mathrm{C}_{60}$; porous silicon; effective potential barrier height

\section{Introduction}

The development of electron microscopy methods required for the comprehensive study and control of the phase composition and surface structure of composite materials is necessary to carry out quantitative analysis of small-scale areas with nanometer spatial resolution. The solution to this problem lies in the field of the development of various methods and techniques for increasing the brightness of an electron gun by using cathodes of various geometries (for example, sharp-tip field emitter arrays (FEA) [1]), as well as creating new materials [2,3]. As an example, one could mention the gradual replacement of wire-type hot emitters based on thoriated tungsten filaments with cathodes made of lanthanum hexaboride and similar materials [4].

One of the most effective electron microscopy methods is the electron energy loss spectroscopy technique (EELS), which is based on the possibility of analyzing and using different behaviors of elastically and inelastically scattered electrons. Elastically scattered electrons are not taken into account in the EELS method, while electrons experiencing inelastic losses practically do not change the direction of their trajectory. The collection of electrons occurs from a local area, comparable in size with the diameter of the electron beam. With the development of field emitters, it became possible to conduct a quantitative analysis in nanoregions, rather than microregions, which, however, required solving a number of problems, including the necessity to enhance the stability of incident electrons 
in terms of energy, to implement energy discriminators with a narrow window, and to increase the electron flux density. As a result, only those electrons are selected that have undergone one-time collisions (i.e., one-time characteristic energy losses), while the receiver detects the electrons that were not deflected and separates them according to their energy.

It should be noted that in the case of modern field emission cathodes, the current density values can reach $10^{8} \mathrm{~A} / \mathrm{m}^{2}$, by several orders of magnitude exceeding the achievable values for classical Richardson-Schottky field enhanced thermionic emitters.

Thus, the problem of increasing the current density of electron sources is relevant, both from a purely scientific perspective and the practical point of view, as a technique that can be successfully utilized to solve technical problems of electron microscopy methods for the analysis of grain boundaries in nanophase materials, which is extremely important for metal and mineral sciences $[4,5]$.

Modern studies [6-8] have indicated that the use of the low-macroscopic field emission phenomenon as a means to reduce the threshold electric field strength magnitudes applied to the cathode makes it possible to obtain comparable current density values in much lower fields (in the range between $1 \mathrm{~V} \cdot \mu \mathrm{m}^{-1}$ and $40 \mathrm{~V} \cdot \mu \mathrm{m}^{-1}$ ) than those for which cold field emission $\left(5 \mathrm{~V} \cdot \mathrm{nm}^{-1}\right)$ is usually observed [9], thus leading to a further increase in the efficiency of this class of devices. For example, the authors of [8] investigated the field emission properties of cathode prototypes based on amorphous nanoporous carbon (NPC). It is assumed that for this structure, the existence of a low-macroscopic field emission phenomenon is due to the presence of conducting nanoparticles, which contribute to the concentration of electric field at their internal boundaries. The authors note that such an effect is preferable from the practical implementation standpoint for a wide range of devices, since, unlike the already mentioned sharp-tip field emitters, the field amplification area is protected from external impacts, such as, for example, ion bombardment. The NPC structures in consideration demonstrated emission properties at threshold field strength values of $2 \mathrm{~V} / \mu \mathrm{m}$ to $3 \mathrm{~V} / \mu \mathrm{m}$.

We chose porous silicon (PS) as a base material for our prototype low-macroscopic field emission cathode due to the prospect of creating a regular PS matrix characterized by a highly specific surface area [10-12], which facilitates its further functionalization [10] as well as the introduction of nanoscale coatings [12,13], quantum objects [14], and thin layers [15] for a wide range of distinctive fields of application, including optoelectronics [16], targeted drug delivery [10], and gas sensing [10]. In addition, earlier studies demonstrated successfully synthesized porous silicon of various spatial configurations and morphology, as well as composite nanostructures based on it [17,18].

It should be noted that while treating the experimental data, many authors have used simplified interpretations of various subjects related to the emission of electrons from composite and amorphous structures. Insufficient attention has been paid towards quantum-size phenomena (for example, the formation of two-electron (2e) and two-hole (2h) centers with negative correlation energy). This fact is all the more important since the analysis of the solutions to optimization problems of modern instrumentation and material processing $[19,20]$, namely the design, manufacture, implementation of devices and prototypes [21], diagnostics (including the development of local micro- and nanodiagnostic systems) [22], as well as control and infocommunication systems [23], indicates the existence of uncertainty and only the relative possibility of its reduction based on reliable quantitative optimizing information in the form of physical models [24-26] describing the relationship between the recorded signals and the interaction processes of various physical fields with matter.

Despite a fairly large number of existing attempts to theoretically describe the process of low-macroscopic field emission, including Latham's model of low-threshold emission [27], Forbes's model of internal field amplification [28], as well as the model of field emission from semiconductor structures with negative electron affinity [29], the mechanisms of this phenomenon still remain unclear. 
Thus, the potential of low-macroscopic field cathodes, characterized by a high electron flux density, as well as a simultaneous decrease in the threshold field strength values for creating electron sources has been widely discussed in literature [30-32].

During our studies, both field emission properties and the structure of novel cathode prototypes predicated on porous silicon functionalized with silver-doped fullerene $\left(\mathrm{C}_{60}\right)$ based structures were studied. A low-macroscopic field emission effect model based on the formation of two-electron (2e) centers with negative correlation energy was proposed.

\section{Materials and Methods}

To obtain a matrix of porous silicon, we used the method of electrochemical anodic etching. Monocrystalline p-type silicon with (100) crystallographic orientation of KDB-12 brand was used as a starting material. At the preparatory stage of the synthesis process, the silicon surface was prepared by three-stage ultrasonic cleaning (in distilled water, acetone, and isopropyl alcohol, respectively). The etching process in an electrolyte based on an aqueous-alcoholic solution of hydrofluoric acid (HF) was carried out using a setup developed at ETU "LETI", the diagram of which is shown in Figure $1[10,18]$. The device included an electrochemical bath, electrodes, an electrolyte, an adjustable sample mounting system, a power supply unit (PSU), and a control module (CM). The sample acted as a working electrode (anode) and was fixed in place with a conductive clamp. The control and change of the etching parameters (namely, the duration and anodizing current density) were carried out using a control module. The porous silicon matrix was synthesized using an etching time of $10 \mathrm{~min}$; the value of the anodizing current density was chosen equal to $20 \mathrm{~mA} / \mathrm{cm}^{2}$.

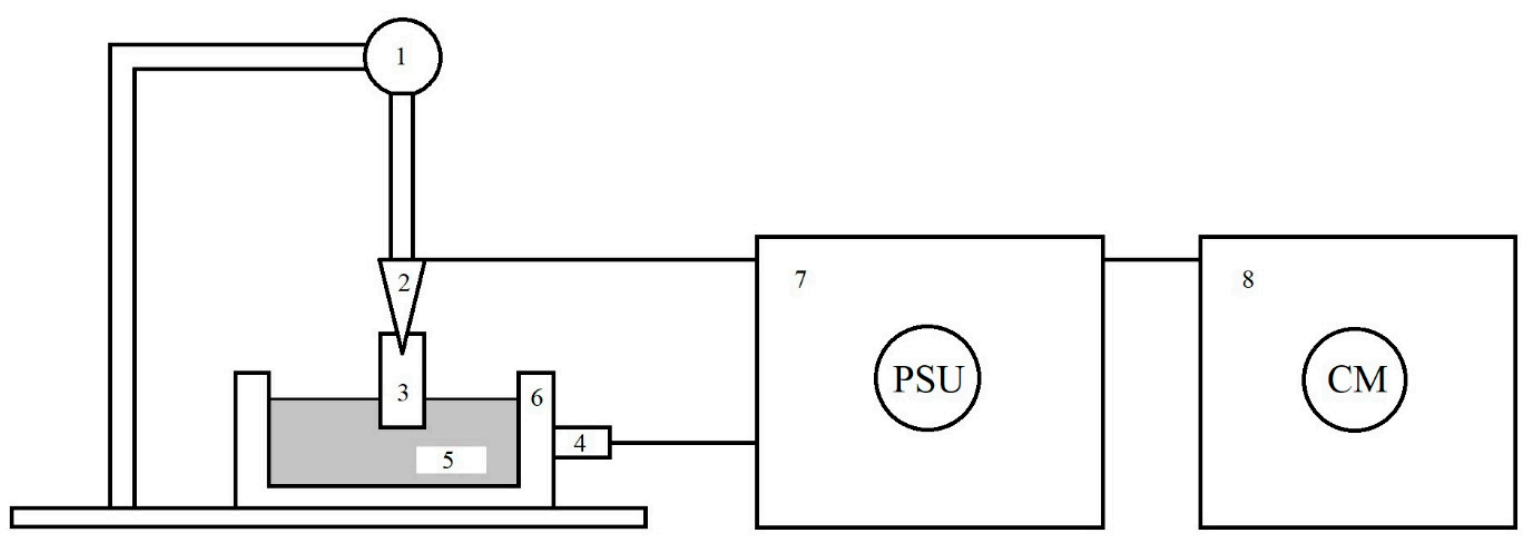

Figure 1. Schematic diagram of the electrochemical etching setup; 1 -adjustable sample fixing system, 2-working electrode (anode), 3-monocrystalline silicon plate, 4-cathode, 5-electrolyte (HF), 6-conducting crucible (glassy carbon), 7-power supply unit, 8-control module.

Scanning electron microscopy of the porous silicon matrix surface and the cathode prototypes, as well as the recording of energy dispersive X-ray spectra, was carried out using a FIB-SEM TESCAN S9251G double-beam scanning electron-ion microscope (4th gen).

In order to realize cathode prototypes, the functionalization of porous silicon substrates was carried out. The deposition of silver-doped fullerene $\mathrm{C}_{60}$-based carbon structures on PS matrix surface was carried out from an aqueous solution using the chemical immersion method. The features and specific parameters of this technology are comprehensively discussed in the distinct research paper of ours [10].

The measurements of the emission characteristics were also carried out. The schematic diagram of the installation is shown in Figure 2 [6]. The device includes a signal generator, a high-voltage power supply unit, a digital oscilloscope, and a vacuum chamber containing an electrode structure. 


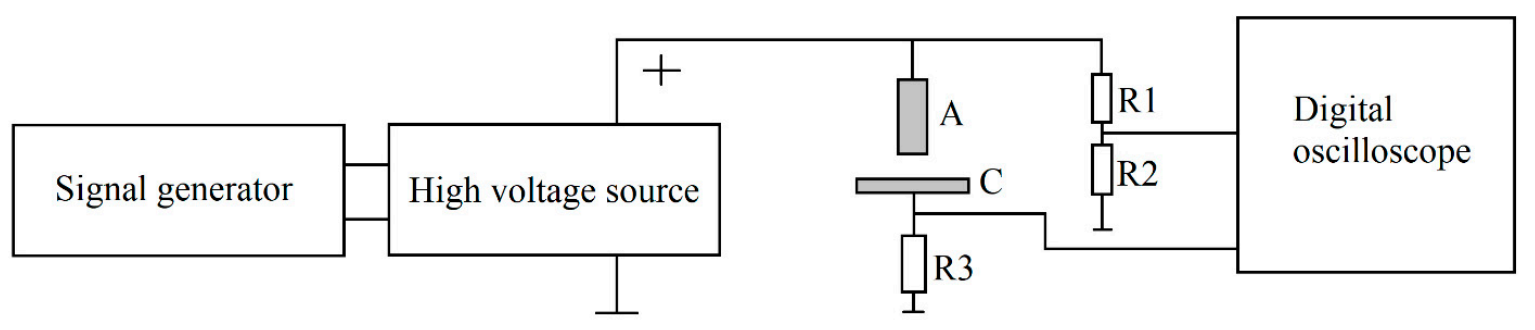

Figure 2. Schematic diagram of the facility used for emission characteristics measurements.

The presented installation allows heating the samples to a temperature of $600{ }^{\circ} \mathrm{C}$. It is possible to perform the measurements of emission characteristics under vacuum conditions with a residual gas pressure of up to $10^{-9}$ Torr. The interelectrode gap is adjustable in the range from $0.2 \mathrm{~mm}$ to $1 \mathrm{~mm}$. The stage as well as the cylindrical anode are made of tantalum (Ta). The anode potential is controlled by applying a positive voltage to it in the range from 0 to $4.5 \mathrm{kV}$.

The emission characteristics were measured at room temperature, the number of cycles was increased (up to at least 5 cycles per measurement) to achieve better accuracy.

In order to remove the residual organic contaminants, each of the samples were briefly heated to a temperature of $200{ }^{\circ} \mathrm{C}$. This procedure contributed to the correction and adjustment of both the emission threshold field magnitudes and the emission current values.

The emission characteristics were measured under high vacuum conditions $\left(10^{-7}\right.$ Torr $)$ using a digital oscilloscope from Velleman Instruments. Observation and recording were carried out using a standard software package in the "transient recorder" mode, allowing the output to be a text file representing a sequence of currents and voltages.

The control of the positive sawtooth signal with a frequency of $12 \mathrm{MHz}$ (the voltage rise and fall times both equaled $35 \mathrm{~s}$ ) supplied to the anode was carried out using a signal generator connected to a high-voltage source.

\section{Results}

During the implementation of the first synthesis stage, a matrix of porous silicon was obtained. The results of studying the matrix by means of energy dispersive $X$-ray spectroscopy (EDS) and scanning electron microscopy are presented in Figures 3 and 4, respectively.

$\operatorname{Si}\left(\mathrm{K}_{\alpha_{1}}\right)$

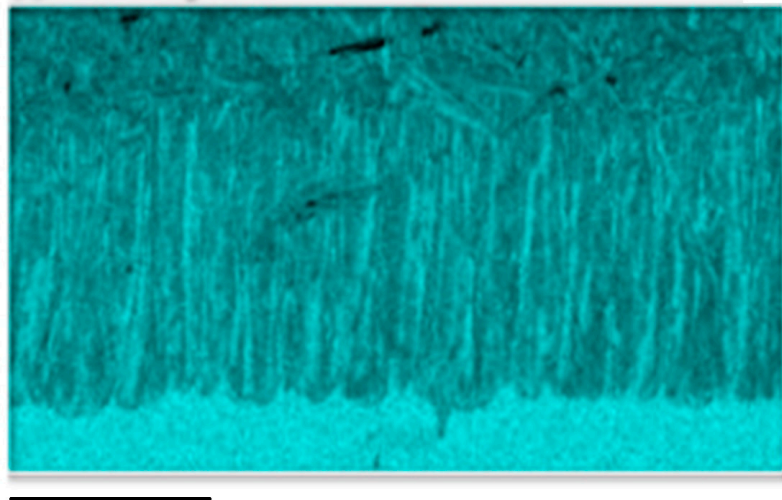

$25 \mu \mathrm{m}$
$\mathrm{O}\left(\mathrm{K}_{\alpha_{1}}\right)$

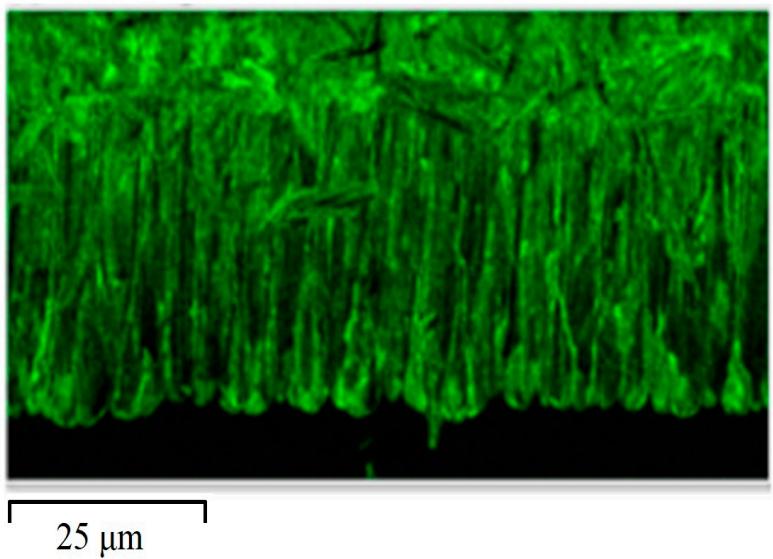

(b)

(a)

Figure 3. Results of energy dispersive X-ray spectroscopy of the initial porous silicon; (a) $\mathrm{Si}\left(\mathrm{K}_{\alpha_{1}}\right.$ line), (b) $\mathrm{O}\left(\mathrm{K}_{\alpha_{1}}\right.$ line). 


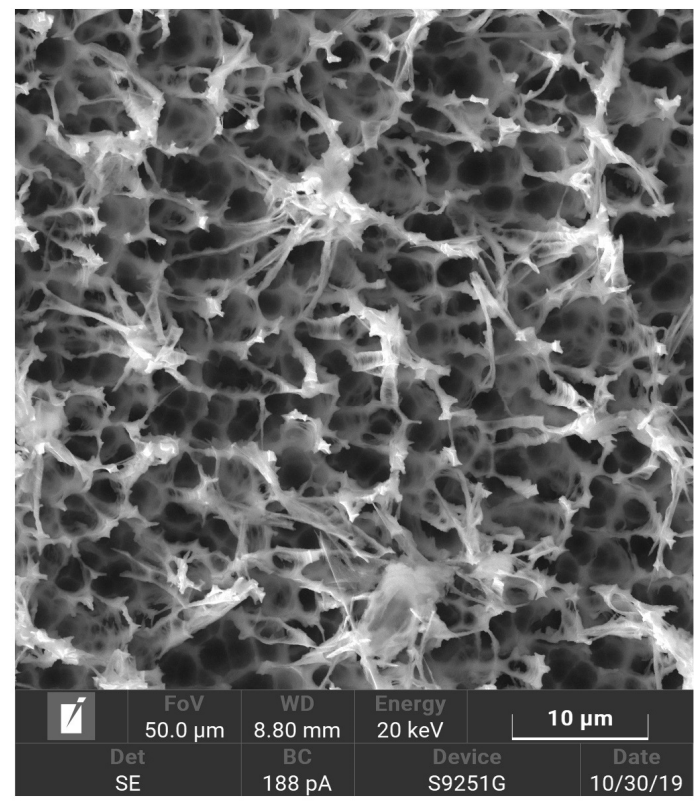

(a)

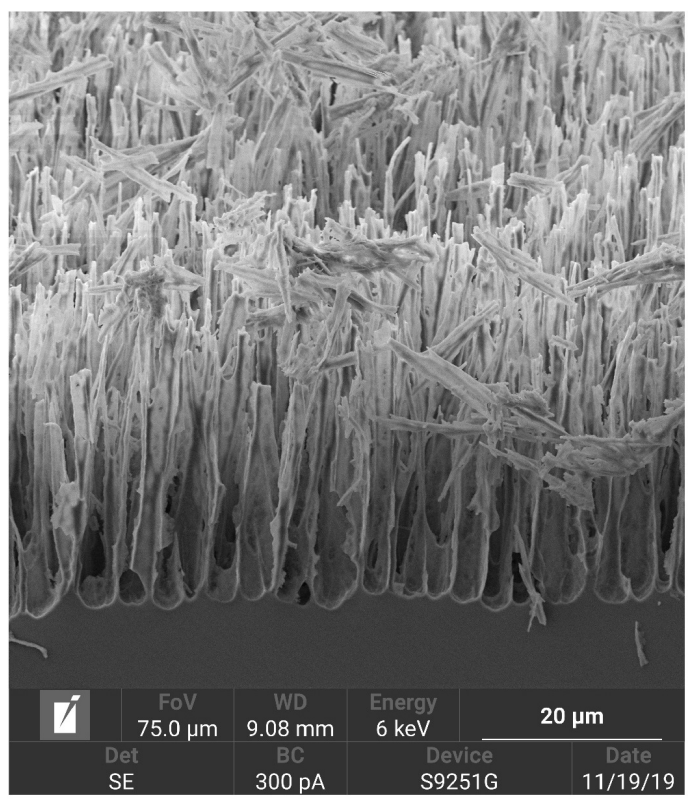

(b)

Figure 4. SEM image of the surface (a) and the cross-section (b) of porous silicon matrix.

According to the data shown in Figure 3, a $\sim 50 \mu \mathrm{m}$ porous layer is formed on the silicon wafer surface. The resulting porous matrix is covered with a thin oxide layer. From the presented SEM images, the structure of the layer formed directly on the matrix of porous silicon is not visible, however, from our earlier studies $[10,11]$ it is known that the surface of porous silicon immediately after the completion of the synthesis stage is covered with a high-resistivity surface thin oxide layer (also known as the "skin layer"), the existence of which is further supported by the results of energy dispersive X-ray spectroscopy investigation of the initial porous silicon matrix.

The thickness of the porous layer, characterized by a regular structure (Figure $4 \mathrm{~b}$ ), reaches $50 \mu \mathrm{m}$, while the pores themselves are separated from each other by thin (no more than $200 \mathrm{~nm}$ ) walls. The resulting structure, which is essentially an array of sharp tip field-emission cathodes, exhibits a high aspect ratio (no less than 100), which promotes effective enhancement of the electric field in the near-surface layer.

Figure 5 contains SEM images and EDS-obtained elemental distribution maps of the prototype cathode (porous silicon, functionalized with silver-doped carbon structures based on $\mathrm{C}_{60}$ ) surface, obtained after the functionalization process occurred during the second stage of synthesis.

Figure 6 contains an SEM image of the prototype cathode cross-section at high magnification. As one can see from the figure, the initial PS surface at this stage is covered with a layer of $\mathrm{C}_{60}$-based Ag-doped nanoscale aggregates with a mean size of $30 \mathrm{~nm}$ (with some of them being as large as approximately $100 \mathrm{~nm}$ ), the elemental composition of which is supported by the results of energy dispersive X-ray spectroscopy shown in Figure 5. 

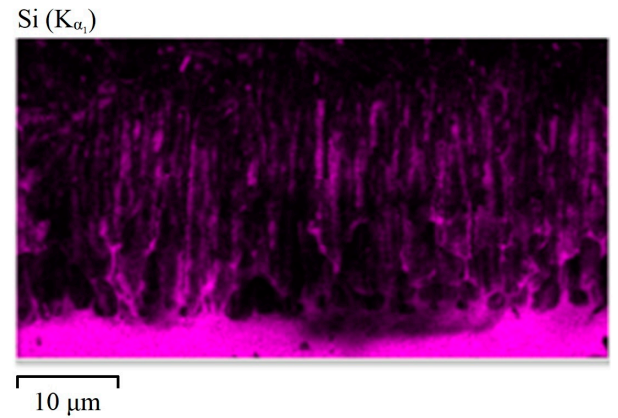

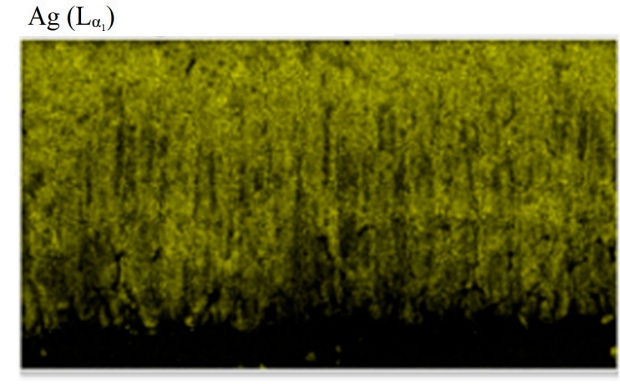

$\longdiv { 1 0 \mu \mathrm { m } }$ (a)

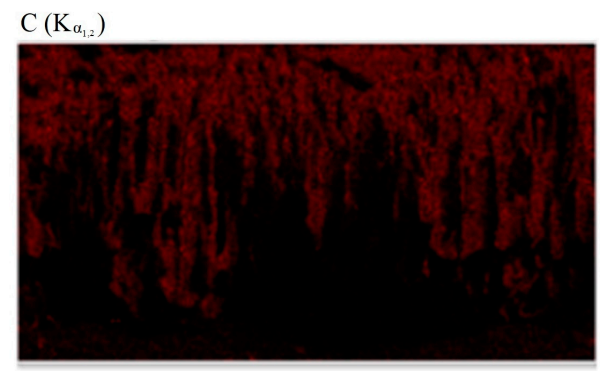

$\longdiv { 1 0 \mu \mathrm { m } }$ (b)

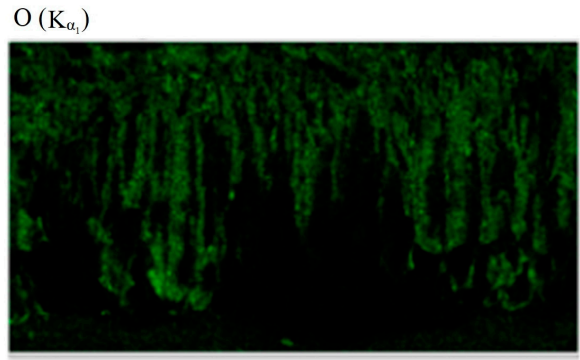

$\longdiv { 1 0 \mu \mathrm { m } }$

(c)

(d)

Figure 5. Results of energy dispersive $\mathrm{X}$-ray spectroscopy of the prototype cathode surface: (a) $\operatorname{Si}\left(\mathrm{K}_{\alpha_{1}}\right.$ line); (b) $\mathrm{Ag}\left(\mathrm{L}_{\alpha_{1}}\right.$ line); (c) $\mathrm{C}\left(\mathrm{K}_{\alpha_{1,2}}\right.$ line); (d) $\mathrm{O}\left(\mathrm{K}_{\alpha_{1}}\right.$ line).

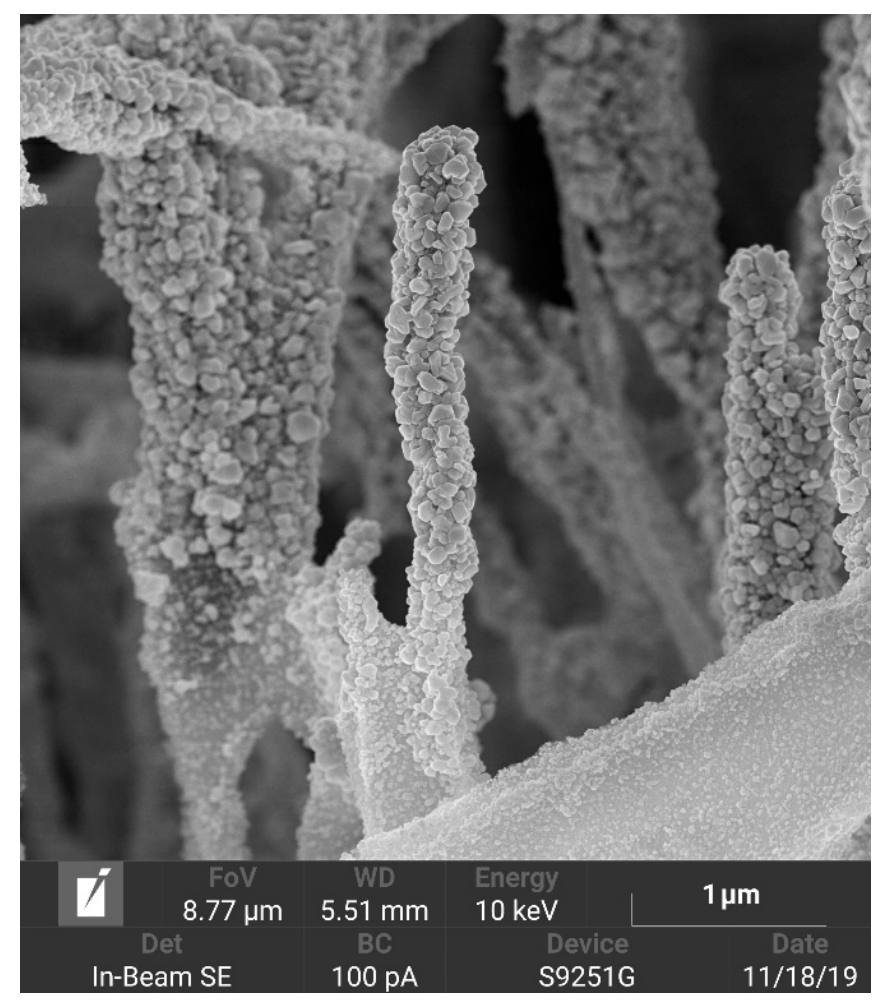

Figure 6. SEM image of the prototype cathode (porous silicon, functionalized with silver-doped carbon structures based on $\mathrm{C}_{60}$ ) cross-section at high magnification. 
The analysis of elemental distribution maps acquired with EDS allowed us to detect signals from silver ( $\mathrm{L}_{\alpha_{1}}$ line) and carbon $\left(\mathrm{K}_{\alpha_{1,2}}\right.$ lines), in addition to the lines from $\mathrm{Si}$ and $\mathrm{O}$ already revealed during the analysis of the initial porous silicon matrix.

Some of the emission characteristics of the prototype are shown in Figure 7 . The exponential dependence of the electron current on the voltage applied between the cathode and the anode is clearly pronounced, which indicates the presence of field emission mechanisms. The threshold field strength was found to be $2.2 \mathrm{~V} / \mu \mathrm{m}$, the maximum applied field in the gap equaled $7.5 \mathrm{~V} / \mu \mathrm{m}$.

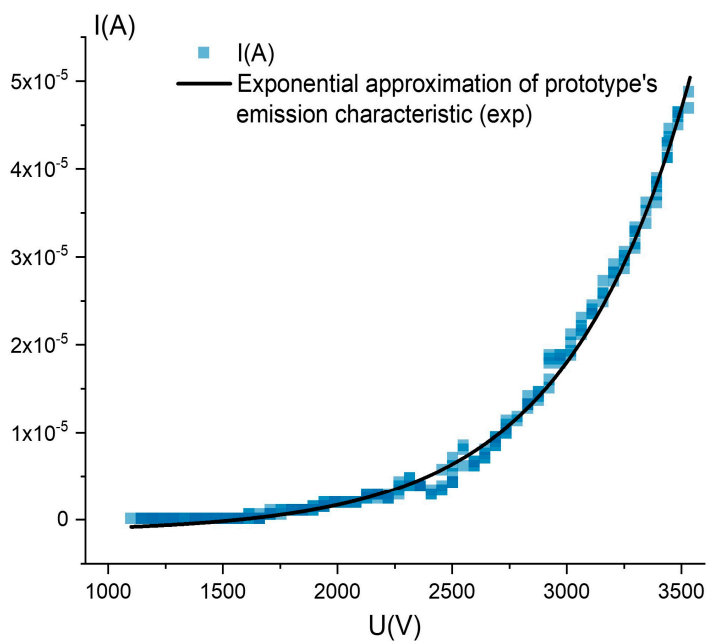

(a)

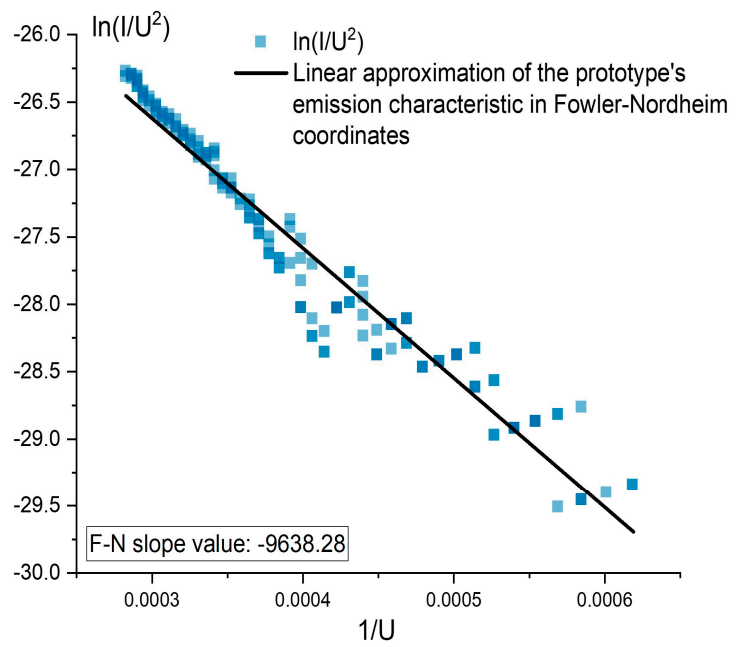

(b)

Figure 7. Emission characteristic of the prototype: (a) 6th measurement cycle, threshold voltage $V_{\text {th }}=1100 \mathrm{~V}$, the maximum voltage applied between the electrodes $V_{\max }=3537.5 \mathrm{~V} ;(\mathbf{b})$ the result of the analysis of the emission characteristics using Fowler-Nordheim-type graphical structures.

It should be noted that modern field emission cathodes based on monocrystalline silicon (n- and p-type) are characterized by threshold field strengths of the order of $1 \mathrm{~V} / \mathrm{nm}$ (depending on the type of conductivity and doping level) [9], which are at least three orders of magnitude higher than the values characteristic to those proposed in the study prototypes.

This effect is due to the presence of a low-macroscopic field emission phenomenon. In order to describe and analyze it, we proposed the model based on Anderson's theory (later developed by Karpov [33,34]) regarding the existence of two-electron (2e) centers with negative correlation energy. In contrast to the previously considered (for example, in [8]) ideas regarding the relationship between the process of dipole's formation and imperfections of graphene-like layers' crystal lattice, the model proposed in this study attempts to use the mechanism of low-macroscopic field emission to describe the process of electron emission from a wide range of carbon materials with a disordered structure (i.e., amorphous materials).

\section{Discussion}

As a starting point for the emission model, one should consider the example of a two-well potential system in crystalline bodies with impurities or defects. When analyzing the potential energy of the displaced to the off-center position (relative to the ideal crystal lattice site) substitutional impurity atom, it is necessary to use the so-called two-well potential. Indeed, in this case, it is energetically more favorable for the impurity atom to be located in one of the off-center positions, the deviation of which can characterize the bond length in the amorphous body. At the same time, tunneling that occurs between two (or 
more) such states leads to the splitting of energy levels characterized by the same energy into two levels with close energy values (Figure 8).

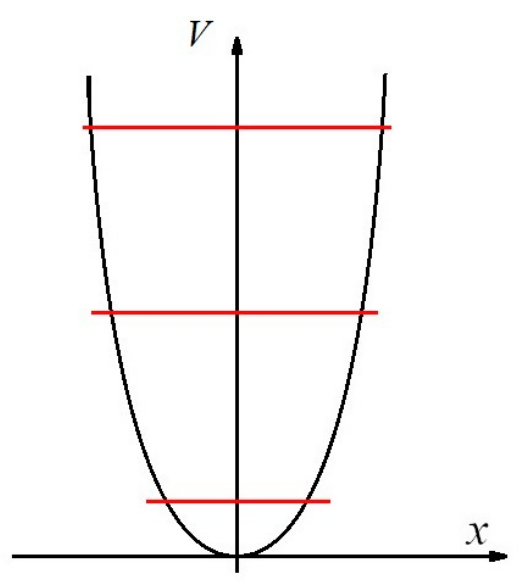

(a)

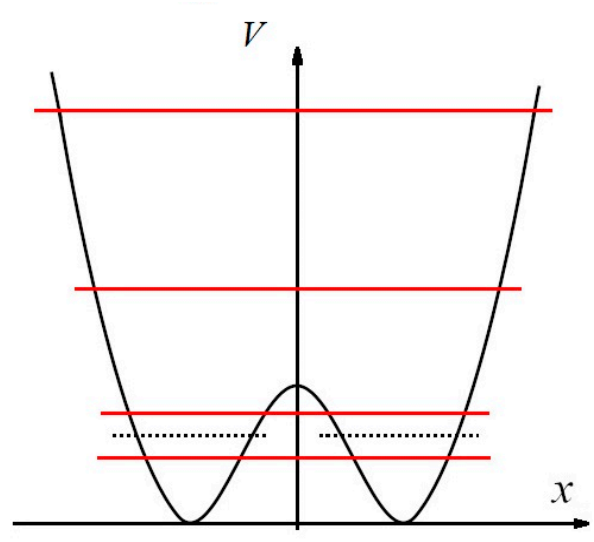

(b)

Figure 8. Energy levels in the case of a single-well (a) and two-well (b) potential.

Thorough consideration of two-well potential emergence in amorphous bodies is presented in [33,34]. Figure 9 contains a schematic representation of the "central" atom's potential in the field of two "neighbors" for a linear chain of three atoms. Here, provided that the distances between atoms 1 and 3 are small, atom 2 is located in a central position corresponding to the minimum value of its potential energy (Figure 9a). A significant increase in the distance between atoms 1 and 3 leads to the modification of atom 2 potential, which starts being characterized by the presence of two minima, between which tunneling is possible (Figure $9 \mathrm{~b}$ ).

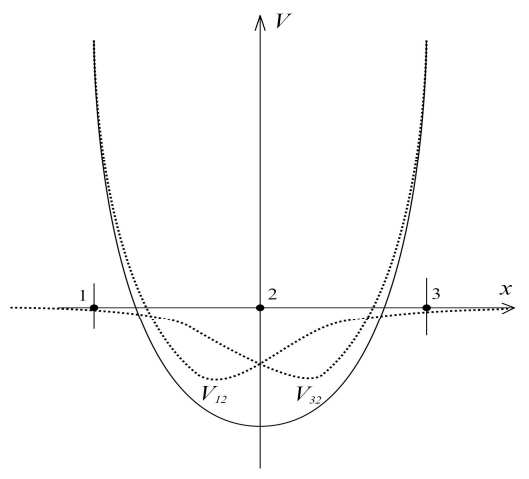

(a)

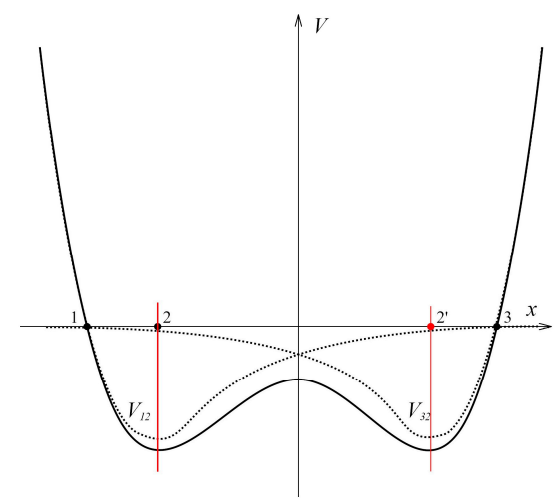

(b)

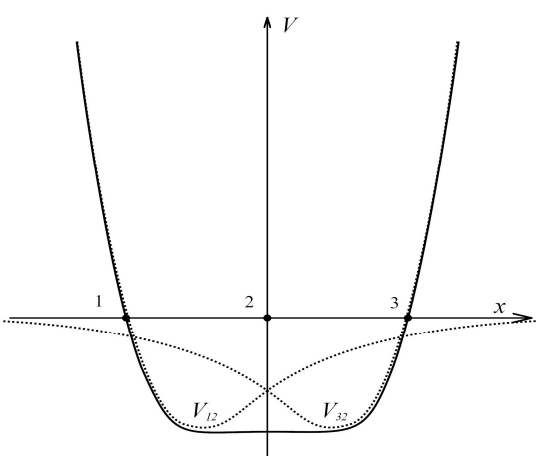

(c)

Figure 9. Interatomic interaction potentials of the middle atom (2) in the field of the outer ones (1 and 3) for a linear chain. (a) the case of relatively small distances between atoms; (b) the case of a two-well potential at large distances: 2 and 2' - two equivalent states at the minimum of the total potential, (c) critical potential.

For an amorphous body, the reason for such an increase lies in the effect of stretching of a particular chain by other atoms (which is confirmed, for example, by the excess of the volume of an amorphous body in relation to a crystalline one).

It should be noted that there is a certain value of the critical distance (and, accordingly, the critical potential) between atoms 1 and 3, at which there is a transition from a single-well 
potential to a two-well one (Figure 9c). In this case, the sign of the second derivative of the atom 2 potential changes at the central point $(x=0)$.

Thus, the critical potentials are characterized by small values of the second derivative. According to [33,34], this effect leads to the appearance of anomalously low values of the quasielastic constant, accompanied by an increase in the effective attraction between localized electrons and, consequently, the formation of states with a negative correlation energy.

As already noted, according to SEM and EDS data, the surface of the PS matrix is fully covered with an amorphous layer of nanosized (from $30 \mathrm{~nm}$ to $100 \mathrm{~nm}$ ) aggregates of silver-doped carbon structures based on $\mathrm{C}_{60}$ fullerene formed during functionalization. In this case, according to the idea put forward by the authors of [7], each of the molecular aggregates of carbon nanostructures is isolated from the rest by tunnel barriers.

The estimate of dipole moment value for the obtained structure was carried out using the methodology proposed in [8]. Hence, $p=q l$, where $q$ is the charge of the two-electron center, $l \approx 30 \mathrm{~nm}$ is the mean size of a certain $\mathrm{C}_{60}$-based aggregate (Figure 6). The obtained values $\left(p=9.6 \times 10^{-27} \mathrm{C} \cdot \mathrm{m}\right)$ lead to the appearance of local fields with a strength of more than $10 \mathrm{~V} / \mathrm{nm}$ under conditions of a relatively low macroscopic field $(2.2 \mathrm{~V} / \mu \mathrm{m})$ and a high concentration of dipole moments. Indeed, the application of the dipole chain model [35] is required in order to estimate the field strength in the form of (1):

$$
F=\left(0.383 / l_{d}^{3}\right)\left(p / \varepsilon_{0}\right)
$$

where $p$ is the magnitude of the two-electron center dipole moment, $C \cdot m ; l_{d}$ is the distance between the dipole centers, $\mathrm{m}$; $\varepsilon_{0}$ is the electric constant, which leads to a value of $F=15.4 \mathrm{~V} / \mathrm{nm}$. Thus, the magnitude of the local field strength near the emitter surface can reach and exceed $10 \mathrm{~V} / \mathrm{nm}$; that is, values sufficient to ensure the emission process.

The processing and analysis of emission characteristics were carried out using the method of Fowler-Nordheim-type graphical structures utilization [28]. The functional connection in the modified coordinates is close to linear (the Pearson correlation coefficient ranged from -0.97 to -0.9 , depending on the measurement cycle), thus indicating the presence of a field-induced emission mechanism.

The calculation of electron emission potential barrier height from the surface of the material was carried out according to the developed technique. Here we have (2):

$$
\ln \left(I / F_{M}^{2}\right)=\ln \left(A_{N} r_{1} a H^{-1} \gamma^{2}\right)-\left(s_{1} b H^{\frac{3}{2}} / \gamma\right) / F_{M}=\ln \left(R_{M}\right)+S_{M} / F_{M}
$$

where $a$ and $b$ are universal constants [28], $A_{N}$ is the total notional emission area, $H$ is the height of the potential barrier for electrons $(\mathrm{eV}), \gamma$ is the local field enhancement factor, $r_{1}$ is the value of the generalized correction factor for the segment cut off on the coordinate axis $(r)$, and $s_{1}$ is the value of the generalized correction factor for the slope $(s) ; \ln \left(R_{M}\right)$ and $S_{M}$, represent the values of the cutoff and the slope of the emission characteristic plotted in Fowler-Nordheim - type coordinates. According to Forbes [28], the value of $s_{1}$ was taken equal to one.

As a result, the slope of the Fowler-Nordheim graph was represented in the following form (3):

$$
S_{M}=-b H^{\frac{3}{2}} / \gamma .
$$

In order to simplify the calculations, an expression equivalent to the one given in (3) was used for calculating the height of the electron emission potential barrier from the surface of the material utilizing the voltage $(\mathrm{V})$ applied between the electrodes (rather than the field strength). Considering each correction factor, the expression could be written in the form (4):

$$
S_{M}=\left(-6.44 \times 10^{9} H^{\frac{3}{2}} / d\right) / \gamma
$$


where $d$ is the interelectrode gap value, $d=5 \times 10^{-4} \mathrm{~m}, \gamma$ is the local field enhancement factor $(\gamma=100)$. The results of the calculation together with the acquired experimental data are summarized in Table 1.

Table 1. Characteristics of a prototype low-macroscopic field emission electrode based on porous silicon, functionalized with silver-doped carbon structures based on $\mathrm{C}_{60}$ fullerene.

\begin{tabular}{|c|c|c|c|c|}
\hline $\begin{array}{l}\text { Measurement } \\
\text { Cycle }\end{array}$ & $\begin{array}{l}\text { Threshold Field } \\
\text { Strength Values, } F_{\text {th }} \\
(\mathrm{V} / \mu \mathrm{m})\end{array}$ & $\begin{array}{l}\text { Achieved Emission } \\
\text { Current, } I_{\max },(\mu \mathrm{A})\end{array}$ & $\begin{array}{l}\text { Maximum (Achieved) } \\
\text { Field Strength in the } \\
\text { Channel, } F_{\max }(\mathrm{V} / \mu \mathrm{m})\end{array}$ & $\begin{array}{c}\text { The Calculated Value of the } \\
\text { Potential Barrier Height for } \\
\text { Electrons } H,(e V)\end{array}$ \\
\hline 1 & 2.2 & 7.4 & 5.2 & 0.32 \\
\hline 2 & 2.2 & 10 & 5.2 & 0.31 \\
\hline 3 & 2.2 & 8.5 & 5.11 & 0.31 \\
\hline 4 & 2.2 & 28.12 & 6.14 & 0.29 \\
\hline 5 & 2.2 & 51.6 & 7.075 & 0.36 \\
\hline 6 & 2.2 & 48.8 & 7.075 & 0.39 \\
\hline 7 & 2.2 & 20.6 & 6.14 & 0.45 \\
\hline 8 & 2.2 & 62.8 & 7.5 & 0.47 \\
\hline
\end{tabular}

It should be noted that despite the processing of prototypes carried out according to the technique presented in the Materials and Methods section (namely, the removal of residual organics by heating the sample up to $200{ }^{\circ} \mathrm{C}$.), the method we have implemented allows for some fluctuations in the measured emission characteristics, since the operation of low-macroscopic field emitters implies the existence of activation and deactivation processes for local emission centers [36].

Owing to the optimal geometric configuration of porous silicon matrix that provides a high local field enhancement factor ( $\gamma$ no less than 100), as well as due to the presence of an amorphous silver-doped $\mathrm{C}_{60}$-based layer consisting of nanosized aggregates located on the matrix surface that ensure the low-macroscopic field emission mechanism conditioned by the formation of two-electron states with a negative correlation energy (the existence of which leads to a further increase in the local field strength), the prototype of the cathode exhibits emission properties that exceed those for classical semiconductor materials (including monocrystalline silicon).

The characteristics of promising samples of field-emission nanostructured cathodes known to date are presented in Table 2.

Table 2. Characteristics of modern and perspective field emission cathodes.

\begin{tabular}{|c|c|c|c|c|}
\hline Emitter Type & $\begin{array}{l}\text { Threshold Field } \\
\text { Strength Values, } F_{\text {th }} \\
(\mathrm{V} / \mu \mathrm{m})\end{array}$ & $\begin{array}{c}\text { Emission Current, } \\
I_{\max },(\mu \mathrm{A})\end{array}$ & $\begin{array}{l}\text { Average Values of the } \\
\text { Height of the Effective } \\
\text { Potential Barrier for } \\
\text { Electrons } H,(e V)\end{array}$ & $\begin{array}{c}\text { Current Density, } \\
\mu \mathrm{A} / \mathrm{cm}^{2}\end{array}$ \\
\hline Carbon nanotubes [37] & $0.2-0.4$ & $0.1-5$ & $0.2-2$ & $2 \times 10^{3}$ \\
\hline $\begin{array}{l}\text { Field emitter arrays } \\
\text { [38] }\end{array}$ & 1 & $2 \times 10^{3}$ & - & $5 \times 10^{5}$ \\
\hline $\begin{array}{c}\text { Monocrystalline silicon } \\
\text { cathodes (n- and } \\
\text { p-type) [9] }\end{array}$ & 1000 & $\begin{aligned} 10^{4}(\text { at } F & =2200 \mathrm{~V} / \mu \mathrm{m}, \\
\mathrm{Ag} & \left.=1 \mathrm{~cm}^{2}\right)\end{aligned}$ & $3.59-4.67$ & $10 \times 10^{3}$ \\
\hline $\begin{array}{c}\text { Nanoporous carbon } \\
{[39]}\end{array}$ & 400 & 1 & - & $0.4 \times 10^{3}$ \\
\hline $\begin{array}{c}\text { Prototype } \\
\text { low-macroscopic field } \\
\text { emission electrodes }\end{array}$ & 2.2 & $62.8($ at $F=7.5 \mathrm{~V} / \mu \mathrm{m})$ & 0.47 & $\begin{array}{l}6.28 \times 10^{3}(\text { at } \\
F=7.5 \mathrm{~V} / \mu \mathrm{m})\end{array}$ \\
\hline
\end{tabular}

The emitter prototypes obtained in the course of our studies are on par with or superior to modern and promising field emitters in a number of crucial parameters. 
It should be noted that metallic field emitter arrays, despite the relative simplicity of the theoretical description and proven manufacturing technologies [38], are very limited in terms of their application as current sources for nanoelectronic devices, primarily due to their incompatibility with complementary technologies for creating metal-oxidesemiconductor structures (CMOS), which are used to manufacture almost all modern integrated devices.

Field emission cathodes based on carbon nanotubes [37] are characterized by diameters of individual structures ranging from $10 \mathrm{~nm}$ to $50 \mathrm{~nm}$, with a packing density of $10^{5}-10^{6} \mathrm{~cm}^{-2}$. Despite the low values of the threshold field strength, due to still unresolved technological difficulties, it is rather challenging to fabricate arrays of identical nanotubes over a large area, and therefore the values of the emission current from cathodes of this type are comparatively small. It should be also noted that the prototype proposed in this study combines both the effect of local field enhancement due to specific morphology of its surface and the phenomenon of low-macroscopic field emission. Even though the phenomenon of low-macroscopic field emission is common to a wide range of materials [28], the use of metal-doped nanostructures based on $C_{60}$ is more effective, since it turned out to be possible to acquire a uniform low-macroscopic field emission layer on the surface of a certain high aspect ratio matrix (in our case porous silicon acted as one). Although currently the technological process of fabricating large-scale carbon nanotube emission arrays presents certain difficulties, some progress has been achieved in this area [40]. Still, the close proximity of nanotubes in these arrays leads to the appearance of such a spatial configuration of the near-surface electrostatic potential, that the effect of local field amplification virtually disappears.

In this regard, the developed prototypes are promising for the creation of highintensity electron beams in low applied electric fields.

As already noted, modern field cathodes based on monocrystalline silicon (n- and p-type) are characterized by values of threshold field strengths of the order of $1 \mathrm{~V} / \mathrm{nm}$ (depending on the type of conductivity and the doping level) [9], thus demonstrating significantly worse emission properties than the prototypes developed in the course of this study.

Moreover, the presence of significant opportunities for doping of the molecular structures based on $\mathrm{C}_{60}$ fullerene with a wide range of chemical elements not limited to silver suggests that the characteristics of the developed prototypes studied in this work can be significantly improved (for example, by using Cs as a doping element, an idea comprehensively realized in the field of thermionic emission, where the problems of electrode surface diagnostics [7], as well as electron distribution function in plasma analysis, are crucial for its further development).

The obtained prototypes due to the low-macroscopic field emission effect occurring in them are superior in terms of emission characteristics (higher emission current density, lower threshold voltage) to regular cathodes based on porous silicon [41,42]. In regard to the use of pure $\mathrm{C}_{60}$ as an emission coating, the studies carried out by the research group from St. Petersburg Polytechnic University have shown that such structures cannot be used as effective field cathodes due to their low stability under the prolonged influence of the electric field and the subsequent electrical breakdown [43]. It should be also noted that the emission characteristics demonstrated by pure $\mathrm{C}_{60}$ films are inferior to those of the materials proposed in this study, both in terms of threshold voltage $\left(8 \mathrm{kV}\right.$ for pure $\mathrm{C}_{60}$ instead of $1.1 \mathrm{kV}$ for our prototypes) and emitted current density $\left(2.5 \times 10^{3} \mu \mathrm{A} / \mathrm{cm}^{2}\right.$ for pure $\mathrm{C}_{60}$ instead of $6.28 \times 10^{3} \mu \mathrm{A} / \mathrm{cm}^{2}$ for our prototypes) [44].

\section{Conclusions}

As a result of our research, the prototype of a low-macroscopic field emission cathode based on porous silicon, functionalized with silver-doped carbon structures based on $\mathrm{C}_{60}$ fullerene, was developed. In terms of its characteristics (including the value of the threshold field strength), the prototype surpasses modern and promising analogues. 
The proposed model of low-macroscopic field emission phenomenon, based on Anderson's theory of two-electron localized states with negative correlation energy, makes it possible to estimate a number of crucial parameters for low-macroscopic field cathodes, including the height of electron emission potential barrier for the emitter material, as well as the values of local near-surface field strength magnitude. Based on the fundamental principles underlying the physical model of emission, it can be assumed that this effect is common to a wide range of emission carbon structures (including graphene-like layers, carbon nanotubes, and layers of molecular aggregates based on $\mathrm{C}_{60}$ fullerene).

Author Contributions: Conceptualization, methodology, formal analysis, in vestigation, writingoriginal draft preparation, writing —-review and editing, visualization, R.S. and Y.S.; investigation, methodology, validation, I.B.; investigation, visualization, P.S.; conceptualization, resources, V.G.; data curation, writing - review and editing, supervision, project administration, A.M. and V.M. All authors have read and agreed to the published version of the manuscript.

Funding: This research received no external funding.

Institutional Review Board Statement: Not applicable.

Informed Consent Statement: Not applicable.

Data Availability Statement: The data presented in this study are available in the article. Initial experimental data are available on request from the corresponding author.

Conflicts of Interest: The authors declare no conflict of interest.

\section{References}

1. Spindt, C.; Holland, C.; Rosengreen, A.; Brodie, I. Field-Emitter Arrays for Vacuum Microelectronics. IEEE Trans. Electron. Devices. 1991, 38, 2355-2363. [CrossRef]

2. Knápek, A.; Dallaev, R.; Burda, D.; Sobola, D.; Allaham, M.; Horáček, M.; Kaspar, P.; Matějka, M.; Mousa, M. Field Emission Properties Of Polymer Graphite Tips Prepared By Membrane Electrochemical Etching. Nanomaterials 2020, 10, 1294. [CrossRef]

3. Giubileo, F.; Di Bartolomeo, A.; Iemmo, L.; Luongo, G.; Urban, F. Field Emission from Carbon Nanostructures. Appl. Sci. 2018, 8, 526. [CrossRef]

4. Reed, S. Electron Microprobe Analysis and Scanning Electron Microscopy in Geology; Cambridge University Press: Cambridge, UK, 2005.

5. Lyalina, L.; Savchenko, Y.; Kadyrova, G.; Selivanova, E. Meliphanite and Leucophanite from the Sakharjok Alkaline Massif (Kola Peninsula). Zapiski RMO 2020, CXLIX, 64-75. [CrossRef]

6. Arkhipov, A.; Eidelman, E.; Zhurkin, A.; Osipov, V.; Gabdullin, P. Low-Field Electron Emission from Carbon Cluster Films: Combined Thermoelectric/Hot-Electron Model of the Phenomenon. Fuller. Nanotub. Carbon Nanostruct. 2019, 28, $286-294$. [CrossRef]

7. Arkhipov, A.; Davydov, S.; Gabdullin, P.; Gnuchev, N.; Kravchik, A.; Krel, S. Field-Induced Electron Emission From Nanoporous Carbons. J. Nanomater. 2014, 2014, 1-9. [CrossRef]

8. Fursey, G.; Polyakov, M.; Bagraev, N.; Zakirov, I.; Nashchekin, A.; Bocharov, V. Low-Threshold Field Emission From Carbon Structures. J. Surf. Investig. X-Ray Synchrotron Neutron Tech. 2019, 13, 814-824. [CrossRef]

9. Patterson, A.; Akinwande, A. Elementary Framework for Cold Field Emission: Incorporation of Quantum-Confinement Effects. J. Appl. Phys. 2013, 114, 234303. [CrossRef]

10. Spivak, Y.; Mjakin, S.; Moshnikov, V.; Panov, M.; Belorus, A.; Bobkov, A. Surface Functionality Features Of Porous Silicon Prepared And Treated In Different Conditions. J. Nanomater. 2016, 2016, 1-8. [CrossRef]

11. Lenshin, A.; Kashkarov, V.; Seredin, P.; Spivak, Y.; Moshnikov, V. XANES and IR spectroscopy study of the electronic structure and chemical composition of porous silicon on n- and p-type substrates. Semiconductors 2011, 45, 1183-1188. [CrossRef]

12. Wu, J.; Li, D.; Wang, K.; Zhang, C.; Hu, X.; Jin, A.; Gu, C.; Zhang, L. High Quality Porous Anodic Alumina Membrane Growing On Micron Thickness Aluminum Film Sputtered On Silicon Substrate. Adv. Mater. Res. 2013, 662, 16-19. [CrossRef]

13. Cunin, F. Functional Coatings of Porous Silicon. In Handbook of Porous Silicon; Canham, L., Ed.; Springer International Publishing: Cham, Switzerland, 2014; pp. 647-663.

14. Hölken, I.; Neubüser, G.; Postica, V.; Bumke, L.; Lupan, O.; Baum, M.; Mishra, Y.; Kienle, L.; Adelung, R. Sacrificial Template Synthesis and Properties of 3D Hollow-Silicon Nano- and Microstructures. ACS Appl. Mater. Interfaces 2016, 8, 20491-20498. [CrossRef] [PubMed]

15. Bolotov, V.; Knyazev, E.; Ponomareva, I.; Kan, V.; Davletkildeev, N.; Ivlev, K.; Roslikov, V. Formation and Properties of the Buried Isolating Silicon-Dioxide Layer in Double-Layer "Porous Silicon-On-Insulator" Structures. Semiconductors 2017, 51, 49-53. [CrossRef]

16. Riahi, R.; Derbali, L.; Ouertani, B.; Ezzaouia, H. Temperature Dependence of Nickel Oxide Effect on the Optoelectronic Properties of Porous Silicon. Appl. Surf. Sci. 2017, 404, 34-39. [CrossRef] 
17. Ren, W.; Wang, Y.; Zhang, Z.; Tan, Q.; Zhong, Z.; Su, F. Carbon-Coated Porous Silicon Composites As High Performance Li-Ion Battery Anode Materials: Can The Production Process Be Cheaper And Greener? J. Mater. Chem. A 2016, 4, 552-560. [CrossRef]

18. Smerdov, R.; Mustafaev, A.; Spivak, Y.; Moshnikov, V. Functionalized Nanostructured Materials for Novel Plasma Energy Systems. Top. Issues Ration. Use Nat. Resour. 2019, 2019, 434-441.

19. Chmilenko, F.; Rastvorova, I. Improvement of Quality of Aluminum Ingots at Electromagnetic Processing. J. Phys. Conf. Ser. 2018, 1118, 012030. [CrossRef]

20. Denisova, O.; Rastvorova, I. Carbon Materials for Immobilization of Biologically Active Substances. Key Eng. Mater. 2020, 836, 52-57. [CrossRef]

21. Shpenst, V. Investigation of the State Of Materials of Power Lines By Multispectral Optical-Electronic Devices. IOP Conf. Ser. Earth Environ. Sci. 2019, 378, 012072. [CrossRef]

22. Nosov, V.; Chaplin, I.; Gilyazetdinov, E.; Grigoriev, E.; Pavlenko, I. Micromechanics, Nanophysics And Non-Destructive Testing Of The Strength Of Structural Materials. Mater. Phys. Mech. 2019, 42, 808-824. [CrossRef]

23. Shpenst, V. Complexation of Telecommunications and Electrical Systems in Mines and Underground Facilities. J. Min. Inst. 2019, 235, 78-87. [CrossRef]

24. Nosov, V.; Artyushchenko, A.; Peretyatko, S.; Khokhlova, E. Multilevel Model of Time Dependences of Acoustic Emission Parameters as the Basis for Nanodiagnostics of the State Of Technical Objects. J. Phys. Conf. Ser. 2020, 1582, 012067. [CrossRef]

25. Shikhov, A.; Potapov, A. The Pattern of Changes in the Velocity of Propagation of Ultrasonic Waves in Frozen Soil Samples during Thawing. J. Phys. Conf. Ser. 2020, 1582, 012079. [CrossRef]

26. Bodunova, Y.; Konoplev, S.; Potapov, A. Propagation And Interaction Of Nonlinear Waves in A Liquid With Gas Bubbles. Acoust. Phys. 2011, 57, 224-229. [CrossRef]

27. Bajic, S.; Mousa, M.; Latham, R. Factors influencing the stability of cold-cathodes formed by coating a planar electrode with a metal-insulator composite. Le J. De Phys. Colloq. 1989, 50, C8-79-C8-84. [CrossRef]

28. Forbes, R. Low-Macroscopic-Field Electron Emission from Carbon Films and Other Electrically Nanostructured Heterogeneous Materials: Hypotheses about Emission Mechanism. Solid-State Electron. 2001, 45, 779-808. [CrossRef]

29. Scheer, J.; van Laar, J. Gaas-Cs: A New Type of Photoemitter. Solid State Commun. 1965, 3, 189-193. [CrossRef]

30. Pan, L. Diamond Sensors and Vacuummicroelectronics. MRS Proc. 1995, 416. [CrossRef]

31. Zhirnov, V.; Hren, J. Electron Emission from Diamond Films. MRS Bull. 1998, 23, 42-48. [CrossRef]

32. Silva, S.; Robertson, J.; Milne, W.; Amaratunga, G. Amorphous Carbon: State Of The Art; World Scientific Publishing: Singapore, 1998.

33. Karpov, V.; Klinger, M.; Ignatiev, P. Atomic Tunneling States and Low-Temperature Anomalies of Thermal Properties in Amorphous Materials. Solid State Commun. 1982, 44, 333-337. [CrossRef]

34. Klinger, M.; Karpov, V. Self-trapping of electron pairs in materials with tunneling states. Electrons in "perfect" covalent glasses. Solid State Commun. 1981, 37, 975-978. [CrossRef]

35. Feynman, R.; Leighton, R.; Sands, M. The Feynman Lectures on Physics; Basic Books: Boulder, CO, USA, 2015; Volume II.

36. Bizyaev, I.; Gabdullin, P.; Arkhipov, A.; Babyuk, V. Study of surface topography and emission properties of thin Mo and Zr films. J. Phys. Conf. Ser. 2019, 1236, 1-5. [CrossRef]

37. Eletskii, A. Carbon Nanotube-Based Electron Field Emitters. Phys. Uspekhi 2010, 53, 863-892. [CrossRef]

38. Sominskii, G.; Tumareva, T.; Taradaev, E.; Mishin, M.; Stepanova, A. Multitip Semiconductor Field Emitters with New-Type Bilayer Protecting Coatings. Tech. Phys. 2015, 60, 133-136. [CrossRef]

39. Bondarenko, V.; Gabdullin, P.; Gnuchev, N.; Davydov, S.; Korablev, V.; Kravchik, A.; Sokolov, V. Emissivity Of Powders Prepared From Nanoporous Carbon. Tech. Phys. 2004, 49, 1360-1363. [CrossRef]

40. Chouhan, V.; Noguchi, T.; Kato, S. Field emission from optimized structure of carbon nanotube field emitter array. J. Appl. Phys. 2016, 119, 134303. [CrossRef]

41. Boswell, E.; Huang, M.; Smith, G.; Wilshaw, P. Characterization of porous silicon field emitter properties. J. Vac. Sci. Technol. B 1996, 14, 1895-1898. [CrossRef]

42. Evtukh, A.; Litovchenko, V.; Litvin, Y.; Efremov, A.; Rassamakin, Y.; Sarikov, A.; Fedin, D. Porous silicon as a material for enhancement of electron field emission. Phys. Chem. Appl. Nanostruct. 2001, 412-416. [CrossRef]

43. Dolzhenko, D.; Zakharova, I.; Borodzulya, V.; Sudar, N. Electroforming and resistive reversible switching effect in polycrystalline fullerene C60 films. J. Phys. Conf. Ser. 2019, 1199, 1-6. [CrossRef]

44. Blank, V.D.; Dybitsky, G.A.; Sheshin, E.P.; Shornikova, A.L. Field emission properties of fullerenes. In Proceedings of the 2010 th International Vacuum Electron Sources Conference and Nanocarbon, Nanjing, China, 14-16 October 2010; pp. 155-164. 